\title{
SWOT (Strengths, Weaknesses, Opportunities, and Threats) Analysis of Strategies for the Development of Beach Sports in Hainan in Combination with PEST (Politics, Economy, Society and Technology) Analysis
}

\author{
Jiangtao $\mathrm{Li}^{1}$,* Xingli $\mathrm{Hu}^{1}$
}

${ }^{1}$ School of Physical Education, University of Sanya, Sanya, Hainan 572022, China

*Corresponding author.

\begin{abstract}
By using SWOT (Strengths, Weaknesses, Opportunities, and Threats) analysis in combination with PEST (Politics, Economy, Society and Technology), this paper analyzes the strengths, weaknesses, opportunities and threats of the development of beach sports in Hainan from the perspectives of policy, economy, society and technology. The research shows that the development of beach sports in Hainan has strengths such as policy support, economic security of sports industry, rich natural resources and distinct project features, but it has weaknesses such as affecting national security, being in an economic transition period, lack of mass base and having insufficient professional talents, etc. While enjoying opportunities provided by the national policy dividends, construction of free trade ports, the hosting of the "Asian Beach Games" and the application of 5G technology for its development, the beach sports face threats such as sub-standard policy implementation, global economic situation, and damage to the ecological environment and impact of advantageous projects. This paper proposes the pioneering strategy, striving strategy, combative strategy and conservative strategy for the development of beach sports in Hainan.
\end{abstract}

Keywords: beach sports, Politics, Economy, Society and Technology - Strengths, Weaknesses, Opportunities, and Threats (PEST-SWOT) analysis, Asian Beach Games, Hainan Free Trade Port

\section{INTRODUCTION}

"Guidelines of the CPC Central Committee and the State Council on Supporting Hainan in Comprehensively Deepening Reform and Opening Up" clearly indicates that Hainan is encouraged and supported to vigorously develop the beach movement. The vigorous development of beach sports in Hainan is a concrete measure and action to promote the economic transformation and upgrading in the field of sports culture, develop the marine economy and implement the strategy of making China a maritime power. It is also an effective "starting point" for Hainan to implement the national "Belt and Road Initiative", promote the construction of Hainan Free Trade Port and Hainan international Consumption Center, and contribute to the success of the 2020 "Asian Beach Games" in Sanya.
The researches of Chinese and foreign scholars on beach sports mainly focus on the feasibility analysis of setting up beach sports course, the analysis of the development status of a certain beach sports and the research on the marketization of beach sports. These studies have laid a theoretical foundation for this paper, but they are not very instructive for the development of beach sports in Hainan. The development of beach sports in Hainan has strengths of resources, policies and opportunities, and can be coupled with the political, economic and social environment of Hainan. Based on this, this paper makes a systematic analysis of the development of beach sports in Hainan through the authoritative and mature theoretical framework of PEST-SWOT development strategy [1], and draws up the development strategy of beach sports in Hainan, so as to provide theoretical reference for promoting the development of beach sports in Hainan.

*Fund: Hainan Scientific Research Grant for Higher Education Institutions (Hnky2020-48); Philosophy and Social Science Planning Project of Hainan Province [HNSK (YB) 19-56]. 


\section{THEORETICAL BASIS OF PEST-SWOT ANALYSIS}

The PEST-SWOT analysis is to integrate PEST analysis into SWOT analysis, and systematically analyze the research object's Strengths and Weaknesses in internal factors, and Opportunities and Threats in external factors from the perspectives of Politics, Economics, Society and Technology [2]. The PESTSWOT analysis is an authoritative and mature theoretical framework for enterprises to carry out strategic management and formulate development strategies. Later, it has been widely used in other fields, such as marketing strategy formulation, eco-tourism development and sports project development. The development of beach sports in Hainan is influenced not only by micro factors such as internal strengths and weaknesses, external opportunities and threats, but also by macro environmental factors such as Hainan's politics, economy, society and technology. Therefore the development strategy for the development of beach sports in Hainan proposed by adopting PEST-SWOT analysis is more convincing and scientific.

\section{PEST-SWOT ANALYSIS OF THE BEACH SPORTS IN HAINAN}

\section{A. Internal strengths}

1) Policy strength: Hainan has obvious strengthsin geographical location and beach resources in the development of beach sports, and beach sports can be well integrated with tourism, health care, culture and other industries for development, which has a very broad prospect. "Guidelines of the CPC Central Committee and the State Council on Supporting Hainan in Comprehensively Deepening Reform and Opening Up" and "Hainan National Sports Tourism Demonstration Zone Development Plan (2020-2025)" clearly points out that it is necessary to strongly encourage and support the development of beach sports in Hainan and strengthen the in-depth integrated development of sports and tourism in Hainan. The principles and paths for the integrated development of Hainan beach sports tourism industry are expounded in order to provide theoretical basis and policy support for the development of Hainan beach sports. In addition, both the "'13th Five-Year Plan' for the Development of the Sports Industry and the Outline of Healthy China 2030 Plan" clearly indicate that different regions are encouraged to develop featured sports with market demands and different regional characteristics [3]. Based on this, vigorous development of beach sports according to the beach resources and the characteristics of beach sports in Hainan province are in line with the needs for the province to actively implement the national policies, serve the optimized development of Hainan's economy and help its people to keep fit.

2) Economic strength: The construction of Hainan Free Trade Port has added wings to the economic development of Hainan. The construction of Hainan free trade port means that Hainan can enjoy a number of preferential tax and financial policies and a relatively free business environment, vigorously promoting the rapid development of logistics, import and export trade, finance and other industries, which contributes to the sustained and healthy development of Hainan's economy. The continuous development of Hainan's sports industry has empowered Hainan's economic development. The sports industry has become the breakthrough point of Hainan's economic development and the pillar industry of national economy in Hainan with strong profit effect and integration ability gradually prominent. The "Implementation Plan for Hainan Province to Build an International Tourism Consumption Center" points out that it is necessary to encourage and supports the integrated development of the beach movement and the tourism industry, guides the consumption of the beach movement, and drives the development of the beach movement industry." The vigorous development of beach sports industry in Hainan stimulates the sport consumption of people and drives the economic growth of Hainan, which reacts on the sustainable development of beach sports in Hainan.

3) Social strength: Hainan province is endowed with the natural resources of tropical and subtropical beaches and is a natural playground for beach sports. Hainan province is the only island with tropical oceanic monsoon climate in China. It has a long summer and no winter in four seasons, with an average annual temperature of $25.7^{\circ} \mathrm{C}$. Besides, the temperature fluctuates less and the climate is mild and humid, which lays a climatic foundation for the development of beach sports. Surrounded by the sea on all sides and with numerous affiliated islands, Hainan province has a coastline of 1,823 kilometers and a coastline with highquality sandy beach resources of about 1,000 kilometers, including the Holiday Beach in Haikou, Yalong Bay in Sanya, Qingshui Bay in Lingshui, Riyue Bay in Wanning, Qizi Bay in Changjiang and so on.

4) Technological strength: With distinctive features, beach sports are a kind of sports activity full of passion and vitality, integrating sports, fashion, leisure and nature. First, beach sports have easy-tolearn techniques and rules, and are interesting and ornamental. It can be used as both a competitive sport and a good recreational activity. Participants of all genders and ages can have a successful experience from it. Second, beach sports require participants to exercise 
barefoot on the beach. Direct contact between the feet and sand and seawater will stimulate the acupoints on the feet, improve the function of the blood circulation system and promote human health. Third, when people exercise on the beach, soft sand will increase the difficulty of running, jumping and other sports, increase human body heat consumption, and thus strengthen the fitness effect. At the same time, the soft sand has a good buffering effect on human body, and can effectively avoid the occurrence of injuries in beach sports Fourth, a harmonious coexistence of man and nature is formed when people exercise in the bright sunshine on the soft beach, with slight sea breeze. Enjoying the pleasure of natural beauty, sports beauty and physical beauty can relieve the pressure of urban life, and promote physical and mental health.

\section{B. Internal weaknesses}

1) Policy weakness: Hainan is China's south gate and has an extremely important and special geographical location. It administers Sansha Island and the waters near the South China Sea, and is the only way which must be passed by the "Maritime Silk Road". It also bears the important task of "Maritime Power Strategy" and "National Key Strategic Service Guarantee Area". In addition, Hainan's coastline and other resources also play an extremely important role in the development of marine economy and deep-sea scientific and technological research. The development of beach movement is inseparable from natural resources such as ocean, beach and coastline, which play an important role in national security and scientific research. Based on this, the development of beach sports in Hainan will certainly yield to national security and deep-sea scientific and technological research, and maximize the value of Hainan's coastline and other resources.

2) Economic weakness: In the past, Hainan relied on the real estate industry, which resulted in the single economic structure, the imbalance of ecological environment and the virtual high prices, which seriously affected the sustainable development of its economy. Having fully implemented the policies and plans of the CPC Central Committee, Hainan strengthened ecological and environmental protection, and worked hard to develop ecological industries such as tourism and modern service industries, so as to optimize and upgrade the economic structure. As Hainan's economic structure is in the stage of optimization and upgrading, all economic indicators in Hainan will be put to the test, making it difficult for sports to develop independently. As the beach sports in Hainan is in its initial stage, with poor self-sustaining ability, so it is difficult for this industry to achieve selfsufficiency. Therefore, in the special period of Hainan's economic structure optimization and upgrading, the development of Hainan beach movement will be affected by the economy.

3) Social weakness: Endowed by unique strengthsin developing beach sports, Hainan hasn't seen ideal development of beach sports. On the one hand, Hainan's local population base is small and the awareness of mass participation in sports is not strong. Moreover, the development of beach sports in Hainan started late and the mass base was weak, so a benign beach sports atmosphere has not yet been formed. On the other hand, the development of beach sports requires not only good beach site resources, but also sufficient urban living infrastructure facilities such as toilets, parking lots and traffic environment near the beach field.

4) Technical weakness: Talents are the foundation and driving force for the development of sports and the development of beach sports in Hainan cannot be separated from professional beach sports talents. There are many beach sports events, each of which has its own technical movements. Correct technical movements are helpful for the masses to have a successful experience and encourage them to persist in participating in beach sports for a long time. Therefore, professional beach sports technical personnel are very important. Some studies show that only beach volleyball and beach football in Hainan beach sports develop well, and corresponding technical talents can meet the needs of sports development, while other sports have not developed well, and have problems such as backward publicity techniques, lack of technical action teaching and backward organization and management. In the final analysis, the lack of technical talents affects the development of beach sports in Hainan.

\section{External opportunities}

1) Policy opportunities: From a "barren island of exile" to a special economic zone, an important fulcrum of "the Belt and Road Initiative" and an "international tourism island", Hainan has been entrusted by the CPC central committee with a mission and an opportunity to become a highland of China's reform and opening up, which fully demonstrates the role of national policies in promoting Hainan's development. Hainan province actively implements national policies and programs, explores beach sports resources, promotes the integrated development of beach sports and tourism industry, and contributes to building Hainan into a free trade port and an international tourism and consumption 
center. Having undertaken "Belt and Road International Beach Soccer Championship Haikou", "Women Beach Volleyball" and "China Corporative Beach Games" and other beach sports events in succession, Hainan effectively publicized the Hainan beach sports, expanded its mass base and enhance its ability to hold beach sports events, so as to help Sanya successfully hold the "Asian Beach Games".

2) Economic opportunities: The construction of Hainan Free Trade Port means that Hainan will open up and upgrade to the outside world. It will help Hainan form a modern and open economic system and stimulate its rapid economic development. With the development of Hainan Free Trade Port, strengthsof the free trade port are gradually emerging. Hainan has signed strategic cooperation agreements with 21 central government enterprises and twenty-three companies will set up headquarters in Hainan with registered capital of 35 billion yuan, which will provide substantial financial support for the rapid economic prosperity and development of the province. The development of beach movement in Hainan province is highly compatible with the national policy and market economy. A good economic environment is the guarantee and opportunity for the development of beach movement in Hainan Province. In return, the development of beach movement in Hainan Province is also an effective means for the implementation of national policies and the promotion of economic construction in Hainan Province.

3) Social opportunities: The sixth "Asian Beach Games" will be held in Sanya, Hainan in 2020. It is the first intercontinental comprehensive Games to be held in Sanya and the only intercontinental comprehensive sports event to be held in China in 2020. It is also a rare opportunity for the development of Beach sports in Hainan. Sanya city will improve 76 urban infrastructure supporting facilities, including beach sports venues and water sports centers, etc., to maximize the smooth holding of the event and provide hardware support for the development of beach sports in Hainan province. Various ways have been used for promoting the "Asian Beach Games" to create an atmosphere of beach sports. In airports, railway stations and urban transport hubs, the propaganda of "Asha Hui" can be seen everywhere; the China International Cultural Industry Fair, the International Flower Tourism Festival, the International Music Festival and other activities are full of elements related to "Asian Beach Games". Holding the "2019 Hainan Beach Sports Carnival", "China Corporative Beach Games" and other quality brand beach sports events in Hainan is, on the one hand to strengthen the beach campaign propaganda and thus promote the
"Asian Beach Games", and on the other hand to promote the beach sports, raise people's health awareness, attract people to experience the fun of the beach sports, increase the mass base of the beach movement, and contribute to the development of the beach sports in Hainan.

4) Technical opportunities: The development of sports cannot be separated from the support of science and technology. Convenient sports equipment, hightech sports equipment and 5G application will vigorously promote the rapid development of beach sports in Hainan. 5G technology has been widely used in the publicity and live broadcast of "Asian Beach Games", enabling the audience to intuitively feel the charm of the beach movement and effectively expanding the mass base of the beach sports " $5 \mathrm{G}+8 \mathrm{~K}$ UHD Video live broadcast" can realize real-time remote live broadcast of HD video, synchronizing the first perspective; "5G+VR Live broadcast" can realize simultaneous multi-camera transmission, and the audience can switch multiple perspectives to create an immersive live match watching experience; "5G+VR experience" can provide virtual and realistic competition experience with the help of VR equipment. The innovation of science and technology has given birth to portable sports equipment and high-tech sports protective equipment, so that people can enjoy beach sports quickly and safely and experience the harmonious coexistence between human and nature.

\section{External threats}

1) Policy threat: What Hainan's development lacks is never policy support, but the ability to grasp policy dividends. The establishment of Hainan province as a special economic zone is the first major historical opportunity for Hainan [4]. From a border island to a benchmark for reform and opening up, Hainan achieved the greatest historical leap in its history. In the 30 years since the construction of Hainan Special Economic Zone, tremendous changes have taken place, but there is still a certain gap between Hainan and Shenzhen, Zhuhai, Xiamen and Shantou, and the expected goal of setting up Special Economic Zones in Hainan has not been achieved [5]. The second historic opportunity for Hainan's development is to build Hainan into an International Tourism Island, give full play to its location and resource advantages, transform its development mode, take tourism industry and modern service industry as pillar industries, optimize and upgrade Hainan's industrial structure and economic institutions, and promote Hainan's rapid and stable economic and social development. The construction of Hainan International Tourism Island has made obvious 
contribution to the economic and social development of Hainan. However, the per capita GDP and per capita disposable income of Hainan have not reached the national average level [5], which has a certain gap with the policy dividend released by the construction of Hainan international tourism Island.

2) Economic threat: The world economy is facing great instability and uncertainty. Economic and trade frictions between China and the US are escalating, and the UK's "Brexit" continues to delay. This has led to difficulties in the development of modern service industries and basic manufacturing industries around the world, and enormous downward pressure on the economy. China's economy will certainly be affected, and Hainan's economy will not be immune. With the global COVID-19 outbreak forcing factories to close and residents to stay at home, global demand is weak and the world economy is volatile. A study shows that in 2020, the daily loss of China's tourism industry is as high as 20 billion yuan, and the direct economic loss of Evergrande Group's film, food and beverage retail and tourism industry during the seven-day Spring Festival is as high as 1 trillion yuan. In the stage of world economic growth slowing down, Chinese economy "gaining momentum" and Hainan's economic structure optimizing, the development of Hainan beach sports will be threatened by Hainan's economic development.

3) Social threat: While beach sports can be well integrated into the tourism industry, forming a new situation of sports tourism, and bringing tourists a new tourism experience, a large number of people flocking to the beach to participate in the beach movement for a long time is bound to destroy the ecological balance of the beach and bring pressure to the marine ecology. With many high-quality tropical and subtropical natural beach resources, Hainan is a natural beach sports holy land. Sporting men in the picture of sand beach, the sea and blue sky forms a realm of harmony and unity between man and nature, which is also the original aspiration of developing beach sports. Hainan is in the stage of optimizing and upgrading its economic structure. Instead of relying on sacrificing the ecological environment in the past to develop real estate to drive economic development, it has transformed to vigorously develop pillar industries such as tourism and modern service industry to ensure a balanced ecological environment. Therefore, the excessive development of beach sports in Hainan will break the ecological balance and harm the sustainable power of its economic development.

4) Technical threat: Hainan is rich in natural resources and rationally distributed. Natural resources such as islands, coastlines, wetlands, rainforests and mysterious $\mathrm{Li}$ and Miao ethnic customs provide favorable geographical environment and cultural conditions for the development of sports such as golf, cycling, marathon, hiking, rafting and expansion. The four branded events including Sanya International Marathon in Hainan have become the name card of Hainan's international tourism island with international influence. Centering on the four branded events in Hainan, the corresponding sports industry and mass sports activities are also developing in full swing in Hainan. However, the development of beach sports in Hainan is unbalanced. Beach volleyball and beach football are well developed, but they are far away from the four brands in Hainan in terms of development scale and influence. Hainan is a place where li, Miao and other ethnic minorities live in compact communities. Traditional ethnic sports such as bamboo pole dance prevail in Hainan, which has a strong impact on the development of beach sports in Hainan.

\section{ANALYSIS ON DEVELOPMENT STRATEGY OF BEACH SPORTS IN HAINAN PROVINCE}

In "Table I", OP represents the policy factor in the external opportunity of the development of Hainan beach sports; OE represents the economic factor in the external opportunity of the development of Hainan beach sports; OS represents the social factor in the external opportunity of the development of Hainan beach sports; OT represents the technical factor in the external opportunity of the development of Hainan beach sports. The factor represented by other monograms can be inferred from this. The development of beach sports in Hainan is influenced by internal and external factors. According to the SWOT method, SO combination strategy, WO combination strategy, ST combination strategy and WT combination strategy can be formed [1]. In each combined strategy, policy, economic, social and technological factors interact to construct the combined strategy. For example, the SO combination strategy is formed by interaction effect between SP, SE, SS and ST with OP, OE, OS and OT. Each strategy must follow the principle of "exploiting strengths, reducing weaknesses, giving play to opportunities and avoiding threats". 
TABLE I. SWOT-PEST MATRIX TABLE OF STRATEGIES FOR THE DEVELOPMENT OF BEACH SPORTS IN HAINAN

\begin{tabular}{|c|c|c|c|c|c|}
\hline \multirow{4}{*}{\multicolumn{2}{|c|}{$\begin{array}{c}\text { External } \\
\text { Environment } \\
\text { Internal environment }\end{array}$}} & \multirow[t]{4}{*}{$\begin{array}{l}\text { Strengths } \\
\text { (S) }\end{array}$} & $\begin{array}{l}\text { SP: sports policy } \\
\text { support }\end{array}$ & \multirow[t]{4}{*}{$\begin{array}{l}\text { Weakness } \\
(W)\end{array}$} & $\begin{array}{l}\text { WP: Interference with } \\
\text { national security }\end{array}$ \\
\hline & & & $\begin{array}{l}\text { SE: Sports industry } \\
\text { guarantee }\end{array}$ & & $\begin{array}{l}\text { WE: being in an economic } \\
\text { transition }\end{array}$ \\
\hline & & & $\begin{array}{l}\text { SS: rich natural } \\
\text { resources }\end{array}$ & & WS: lack of mass base \\
\hline & & & $\begin{array}{l}\text { ST: distinctive project } \\
\text { features }\end{array}$ & & $\begin{array}{l}\text { WT: lack of professional } \\
\text { talents }\end{array}$ \\
\hline \multirow[t]{4}{*}{$\begin{array}{l}\text { Opportunities } \\
(\mathrm{O})\end{array}$} & $\begin{array}{l}\text { OP: National policy } \\
\text { dividend }\end{array}$ & \multirow{4}{*}{\multicolumn{2}{|c|}{$\begin{array}{l}\text { SO strategies (Pioneering strategy): } \\
\text { giving play to strengths }\end{array}$}} & \multirow{4}{*}{\multicolumn{2}{|c|}{$\begin{array}{l}\text { WO strategy: taking advantage of strengths } \\
\text { and reducing weaknesss }\end{array}$}} \\
\hline & $\begin{array}{l}\text { OE: free trade port } \\
\text { construction }\end{array}$ & & & & \\
\hline & $\begin{array}{l}\text { OS: holding the "Asian } \\
\text { Beach Games" }\end{array}$ & & & & \\
\hline & $\begin{array}{l}\text { OT: application of } 5 \mathrm{G} \\
\text { technology }\end{array}$ & & & & \\
\hline \multirow[t]{4}{*}{$\begin{array}{l}\text { Threats } \\
\quad(T)\end{array}$} & $\begin{array}{l}\text { TP: } \\
\text { implementation of the } \\
\text { policy is not practical }\end{array}$ & \multirow{4}{*}{\multicolumn{2}{|c|}{$\begin{array}{l}\text { ST strategy (combative strategy): } \\
\text { playing to the strengths and } \\
\text { avoiding threats }\end{array}$}} & \multirow{4}{*}{\multicolumn{2}{|c|}{$\begin{array}{l}\text { WT strategy (conservative strategy): } \\
\text { minimizing weaknesses and avoiding threats }\end{array}$}} \\
\hline & $\begin{array}{l}\text { TE: global economic } \\
\text { situation }\end{array}$ & & & & \\
\hline & $\begin{array}{l}\text { TS: destruction of } \\
\text { ecological environment }\end{array}$ & & & & \\
\hline & $\begin{array}{l}\text { TT: advantage project } \\
\text { impact }\end{array}$ & & & & \\
\hline
\end{tabular}

\section{A. SO strategy: pioneering strategy}

SO strategy is a pioneering strategy, which is generated by the interaction between the strengths of the internal environment and the opportunities of the external environment. It requires the strengths of the internal environment and the opportunities of the external environment to be brought into play. The SWOT-PEST matrix table of strategies for the development of beach sports in Hainan ("Table I") shows that the SO strategy of beach sports development in Hainan means playing sports policy support, the guarantee of the sports industry, abundance in natural resources and distinct characteristics of the beach sports project as well as other strengths and using opportunities of national policy bonus, free trade port construction in Hainan, "Asian Beach Games" held in Hainan and 5G technology application, so as to make the internal strengths of Hainan beach sports development and external opportunities to interact with each other and work together to promote the vigorous development of beach sports in Hainan.

\section{B. ST strategy: combative strategy}

ST strategy is a combative strategy, which is generated by the interaction between the strengths of the internal environment and the threats of the external environment. It requires to give play to the strengths of the internal environment and avoid the threats of the external environment. The SWOT-PEST matrix table of strategies for the development of beach sports in Hainan ("Table I") shows that the ST strategy of beach sports development in Hainan means playing sports policy support, the guarantee of the sports industry, abundance in natural resources and distinct characteristics of the beach sports project as well as other strengths and avoiding or mitigating threats such as inadequate implementation of relevant policies in Hainan, the impact of global economic situation, tendency to cause damage to the ecological environment and impact of advantageous projects, so as to promote the healthy development of beach sports in Hainan.

\section{WO strategy: striving strategy}

WO strategy refers to striving strategy, which is a strategy generated by the interaction between the weaknesses of the internal environment and the opportunities of the external environment. It requires the use of the opportunities of the external environment and reduce the weaknesses of the internal environment. ("Table I") shows that the WO strategy of beach sports development in Hainan means using opportunities of national policy bonus, free trade port construction in Hainan, "Asian Beach Games" held in Hainan and 5G technology application and strengthening the "internal training and external introduction" of Hainan beach sports professionals, promoting the publicity effect, expanding the mass base, making a clear distinction between military land and living land, supporting the construction of national border security and actively promoting the integrated development of beach sports and tourism, so as to create a good economic 
environment to facilitate the sustainable and healthy development of Hainan beach sports.

\section{WT strategy: conservative strategy}

WT strategy is a conservative strategy, which is a strategy generated by the interaction between the weaknesses of the internal environment and the threats of the external environment. It requires reducing the weaknesses of the internal environment and avoiding the threats of the external environment. ("Table I") shows that the WT strategy of the beach sports development in Hainan means strengthening the "internal training and external introduction" of Hainan beach sports professionals, promoting the publicity effect, expanding the mass base, making a clear distinction between military land and living land, supporting the construction of national border security and actively promoting the integrated development of beach sports and tourism, so as to create a good economic environment to facilitate the sustainable and healthy development of Hainan beach sports in the context of inadequate implementation of relevant policies in Hainan, impact of the global economy, tendency to cause damage to the ecological environment and the impact of advantageous projects as well as other threats.

\section{CONCLUSION}

The development of beach sports in Hainan is of great significance to promoting the economic transformation and upgrading of Hainan, facilitating the construction of Hainan international sports tourism demonstration zone and the successful hosting of the "Asian Beach Games" in Sanya in 2020. The strengths, weaknesses, opportunities and threats of the development of Hainan Beach sports together with Hainan's political, economic, social and technological environment affect the development of Hainan beach sports. Considering the political, economic, social and technological environment of Hainan, based on the SWOT analysis principle, the development strategies of the beach sports in Hainan are drawn up, including pioneering strategy, striving strategy, combative strategy and conservative strategy, so as to effectively promote the sustainable and healthy development of the beach movement in Hainan.

\section{References}

[1] Yu Bo, Fan Zui. SWOT Analysis of Advanced Manufacturing Industry Development Strategy Adding Pest in China [J]. Nanjing Journal of Social Sciences, 2011(07): 34-40. (in Chinese)

[2] Fu Bing, Wang Jiahong. Research on the Introduction of Information Disclosure System in China's Public Sports Service Construction $[\mathrm{J}]$. Journal of Beijing Sport University, 2008,41(05): 9-15+39. (in Chinese)
[3] Bai Jin-xiang. Review and Prospect of China's Ethnic Traditional Sports Reform and Development in the past 40 years [J]. Journal of Shanghai University of Sport, 2008, 42(05): 9-14. (in Chinese)

[4] Zhang Xuxin. Research on Moral Support for Construction of Hainan International Tourism Island [M] Beijing: People's Publishing House, 2017. 06. (in Chinese)

[5] Wang Mingchu. The Historical Evolution and Enlightenment of Hainan Province since Its Establishment as a Special Economic Zone [J]. Journal of Hainan Normal University (Social Science), 2019, 32(04): 7-14. (in Chinese)

[6] Gu Song. Research on the Development Strategy of Chinese Competitive Volleyball in the New Era [D]. Doctoral thesis of Beijing Sport University, 2012 (in Chinese)

[7] Research Group of China (Hainan) Reform and Development Research Institute, Chi Fulin. A Tentative Plan for Hainan to Explore the construction of a Free Trade Port with Chinese Characteristics [J]. Reform, 2019(04): 27-38. (in Chinese)

[8] Hainan Action Plan for Millions of Talents (2018-2025) $[\mathrm{EB} / \mathrm{OL}] . \quad(2018-07-04) \quad[2020 \quad 03 \quad 31]$ http://www.hainan.gov.cn/data/hnzb/2018/07/4069. (in Chinese)

[9] hao Libo. Research on Public Service System with Chinese Characteristics [M] Beijing: People's Publishing House, October 2015. (in Chinese) 